\title{
Study of Constructive Interpreting Teaching Mode Based on Real Projects*
}

\author{
Juju Wang \\ School of Foreign Studies \\ Qi Lu Normal University \\ Jinan, China 250013
}

\begin{abstract}
The traditional interpreting mode and concepts cannot meet the need of high-quality interpreting talents because the increasing demand of interpreters from all walks of life. The learner-centered constructivism theory states learning is an active operation closely related with context in which knowledge and ability could be constructed rather than trained. A new interpreting teaching mode based on real projects is conceived according to the concept of the constructivism from the perspective of teaching contents and managements with the aim of promoting students' interpreting ability and quality.
\end{abstract}

Keywords-constructivism; interpreting teaching mode; real projects

\section{INTRODUCTION}

The need for high standard translating talents is increasing from various social businesses. People's attention turns on the translational products' quality and translator's comprehensive ability. Under the context of globalization, educators of English and translation should explore new teaching mode to cope with the new requirements and targets. The English majored students cultivated in the traditional mode cannot meet the needs of the international society.

The core of the translating teaching for English majors is to train the students' translating ability and to strengthen their cognition for translation. Therefore, it is the translating teaching that should be blamed for in case that the students' translating ability could not meet the talents market's requirement. It turns out that it is the traditional translating teaching mode which is teacher centered and textbook based that limits the students' development of interpreting ability.

Although English majored teaching reform was not so massive compared with the college English, the training for English majors was eagerly demanded with international progressing of our education. Based on both domestic and foreign studies and changes in translating teaching reform recent years, Lin Kenan pointed out that class teaching should turn from teacher-oriented to students-oriented, while context simulated teaching methods could be applied targeted with students' innovation training(Lin Kenan, 2000). This paper tries to illustrate the necessity, feasibility and

*The achievement of Shandong Social Science Planning Study Project "The Strategic Study of College English Teaching Based on Learning Styles" (16CZWJ55). operability of a new teaching mode from the constructivism theory and to explore how to complete some real projects in translation teaching.

\section{CHINESE INTERPRETING TEACHING'S CURRENT SITUATION AND PROBLEMS}

Domestic experts have studied the problems existing in interpreting teaching in recent years. Lu Xinzhao had analyzed current problems in Chinese interpreting teaching and came up with the integrated training mode, but he didn't explore from the level of interpreting effect. The current situation and problems should be analyzed and solved from the perspectives of teaching mode and method, class organization and effects and the students.

The normal teaching process in our Chinese traditional translating class consists of doing exercises, checking the answers and introducing the translational tips. The teachercentered situation and mode leads the students cannot fully participate in the class which most dominated by the teachers. The textbooks used in translation class are picked by the teachers casually or by the school which lack practical experiences and innovation. Teachers' assessments for students' translation are subjective. The invariable teaching mode resulted in the students' unsatisfactory translational ability and inefficient teaching effects. The experts and educators are aware that updating the teaching concept and changing the teacher and student position are the solution to raise the translational effects. Hence the real context intimating and translational processing mode were used to combine the market requirements and the teaching.

There were divergent opinions about the interpreting teaching mode and method among Chinese scholars. Interpreting has not been separated from the translation in Chinese universities. Teachers often introduce the translational tips and let the students translate some materials orally. While other interpreting classes are not separated from oral English which focused on the words and phrase practice. Films and some videos of conference interpreting are often played and observed by the students which converted the interpreting class into the video appreciating class. The students are required to learn some new words and to interpret some sentences repeated by the recording, which obeyed the interpreting training principle. Wang Junhua once found that the information which practiced by the students 
lacks of background and context and separated by the communicative environment. This kind of teaching mode is the misunderstanding of the real interpreting need (Wang Junhua, 2003).

The common problems existing in interpreting class organization of Chinese universities are arbitrary class activities and unscientific teaching patterns. Duo to the hysteretic interpreting teaching theory and method, teaching organizations in different universities are various. The students' listening and speaking competence is not qualified to accomplish some tasks in society. The investigation conducted in Shanghai International Studies University showed us that $4.40 \%$ respondents could understand English news with normal speed, while $4.74 \%$ could understand special English of VOA (Mei Deming, 2004).

In summary, the dominant problems of the students majored in interpretation are as follows. First, they focused on theory study and lacked real practice. There is no distinction between application-oriented and researchoriented study. What's more, the students' self-studying ability is quite poor because they have no correct studying attitude and motivation. They are easy to be distracted by subjective or objective elements and unclear about the interpreting occupation. The most outstanding problem is their unsatisfied interpreting effects. They lack of exclusive knowledge and professional training led them not unqualified to complete the tasks in real interpreting work.

\section{CONSTRUCTIVISM AS THE THEORETICAL FOUNDATION}

As a new learning theory, constructivism absorbed both behaviourism and cognitivism and was developed and put forward by Vygotsky. According to constructivism, language acquiring is a reconstruction course of cognitive structure and a continuous message and knowledge processing which involves experiencing, discovering and creating. Behaviourism stresses the important role of "stimulating and response". The students passively receive the messages, while the teachers are the source of fundamental knowledge. The students' psychological process of understanding is omitted. Students' internal processing and absorbing of the external stimulation is emphasized by the cognitivism. Knowledge acquiring is a both subjective and objective course in which learner's personal converting and processing is the key point from constructivism theory. Students' personal experience and active joining plays an important role in the teaching activity.

Some domestic scholars applied constructivism into the foreign language learning. He Kekang illustrated that the basic point of the constructivism theory was knowledge acquired not by the teacher's teaching but by constructive way with other's help and necessary learning resources under a certain social cultural context (He Kekang, 2001). Certain context with social and cultural background enables the learners to use their cognitive ability and to acquire knowledge by the constructive way (Kiraly, 2000). The new interpreting teaching mode is based on the fundamental meaning and condition of constructivism.
The learner-centered transformation is constructivism's priority. In this theory, learning is considered as an active operation connected with context in which knowledge and ability could only be constructed rather than trained. The constructive course considers existing knowledge organization as a basis and closely related with the context. The new interpreting teaching mode will place the students in the real project's linguistic context, in which the students can make full use of their initiative and creativeness. After learning all the theoretic courses, the students will be trained with the real and abundant projects which can grasp some implicit knowledge compared with the traditional interpreting class.

\section{THE RECONSTRUCTION OF INTERPRETING TEACHING MODEL}

Scholars in the translational circle attach great importance on the translation teaching as the professionalism of translation under the condition of globalization. The Chinese government has increased the number of universities with undergraduate translational teaching position to 152 and universities with MTI to 206 from 2014. Teaching objective indicated in the new syllabus for English majors is the graduated students should be qualified to accomplish general difficult translating and interpreting in the areas of foreign affairs, business, culture, education, technology and military affairs. The students can perceive the interpreting profession and training while doing the real projects, which can realize the teaching objective intuitively.

\section{A. The Contents of the Constructive Interpreting Teaching Mode}

In recent years, the interpreting teachers have discussed and concluded many practical and valuable opinions in concrete interpreting teaching contents. Zhong Weihe listed seven items based on both domestic and foreign demonstration, which concludes understanding language and information, memorizing language and information, coordinating with numerous tasks, taking and reading the interpreting notes, interpreting tips and knowledge, tips and performance of gestures, language and information expression ( Zhong Weihe, 2012). The constructive teaching mode based on the real tasks optimized the seven items and increased 4 contents: preparation before interpreting, real tasks practice, error correction from teachers and teaching reflection.

Constructive teaching mode requires the interpreting teacher to train the students before practice the real task. The students should be informed the schedule, the topic, the politic, economic, educational, historic, cultural background of the foreigners, foreign affairs etiquette, diplomatic policy, interpreting practical tips and coping strategies.

Real task practice is the critical part in the constructive teaching mode, in which students should face real English linguistic environment, real interpreting service objects, and real meeting environment. As a good case in point, tourist interpreter should conduct one to one service. The students will accept challenges which should be completed by their own knowledge and abilities according with the real situation. 
The breakthrough of constructive mode is reflected in this part, in which the students are completely self-helping without the teacher's assistant.

The teacher's error correction part should not be missed which can be arranged after one day's practice. Students should be called together at night and communicate with the teacher and other ones of the problems met in the day which can be solved by the teacher. Each students can share the harvest and experience which revalued by the teacher. Teachers should be aware that the students could not have the idea of dependent on the teacher, and they cannot correct students' errors excessively in case they lose confidence. Students can make interpreting journals to describe their thoughts in a casual and free environment. Both the discussion and the interpreting modification after discussion can be recorded with the focus of "how to interpret" and "why to choose that strategy". In this part, we focus on training students' ability like self-monitoring, self-reflection, dependent thinking and cooperation with others. A large amount of real self-reflecting information can be recorded in the journal, from which teachers can discover each student's mistakes and errors that could be corrected by the teacher.

Teaching reflection is the last part of constructive teaching mode. Experiences without reflection are quite superficial which can restrict teacher and students' development. Teaching reflection is based on the investigation of the previous teaching parts, which can come up with the solution for the interpreting problems. The successful reflection covers every part of the teaching including objectives, syllabus, contents, assessment, discipline construction, talents' training and teaching research.

\section{B. The Management of the Constructive Interpreting Teaching Mode}

From the perspective of teaching objective, contents and process, constructive interpreting teaching mode has many distinctions with traditional one. However, both of the two modes are aimed at improving interpreting quality and students' interpreting ability. Teachers and the students should uphold correct concepts and principles. Students should be aquatinted with the teaching objectives and their developing directions. Teachers' requests cannot be too strict or too loose, who should be aware that students are not trained to be the UN interpreters while the supervision upon them should not be deregulated. The teaching management in the constructive teaching mode appears significant under these concept and principles.

Finding the suitable interpreting tasks is the premise of the teaching. In her article, Wang Xiangling once pointed out "Under the condition of lacking of interpreting textbooks, teachers can lead the students to explore the local translational market in order to find the real interpreting tasks which are suitable for students' ability and requirement."(Wang Xiangling, 2008) The difficulty of the task, the concrete requests, deadline of the task, and the schedule of students' courses are all taken into consideration by the teacher. Teachers can communicate with the school or the government who can provide us qualified interpreting projects for the students.

The teaching management will move to the task controlling part after the project is confirmed, which is the critical and most difficult one. First, teachers should inform the students not only the translational standards and suggestions but also the foreign etiquette, foreign affairs strategy, solution for some emergencies. During the task, teachers should learn and solve the problems for the students at the end of each day. Teachers also supervise the interpreting quality while students do the practice in the real task. In traditional interpreting class, as the coordinator, manager and organizer, the teacher's main task is to introduce the learning method to the students, to organize the students practice and check their learning effects. Interpreting teacher's work is far more than these in the constructive class based on the real projects. The problems met in the real context are not only limited in the linguistic structures but also of the psychological quality, professional ethics accomplishment, humanistic quality, communicative ability and coordinated ability. Teacher should give students directions and managements on these aspects in order to accomplish successful communication.

Interpreting assessment and teaching reflection are the last step when the task is finished. According to the teaching syllabus, teacher can check whether students' interpreting quality has been improved and meet the teaching requirement through some quiz. The students' attendance, performance in the task, feedback from the customers can all be recorded and assessed in the end of the semester. The constructive mode should be evaluated from the aspects of feasibility, maneuverability through investigation or interviews.

\section{CONCLUSION}

Chen Jianlin once gave us the definition of the teaching mode. Foreign language teaching mode is the way for teaching activity and method directed by certain foreign language teaching theory and practice framework in order to achieve certain objectives. It is the mediation which applies foreign language teaching theory into teaching activity and operation. Therefore, mode and theory are closely related (Chen Jianlin, 2010).

Constructive interpreting teaching mode based on real projects was put forward in this paper. After the analyzing of Chinese current interpreting teaching mode and comparison with traditional teaching mode, new teaching contents are added into the traditional one. The managements before, during and after the task practicing are also listed. The assessment system was also discussed at the last part of this paper. The core of the constructive teaching mode is combining the real projects with the teaching class. There are some other considerations like whether the school's policy supports the mode, whether students' personal schedule conflicts with the task, whether the students are willing to participate, how to safeguard students' security and confidence. All the problems could be solved in the later research to make the mode more practical and meet the 
domestic and foreign interpreting teaching developing regulation.

\section{REFERENCES}

[1] Kiraly, D, A Social Constructivist Approach to Translator Education: Empowerment from Theory to Practice [M]. St. Jerome Publishing. Manchester, UK, 2000: 42

[2] Chen Jianlin. Study on the Integration of Internet and Foreign Language Teaching [J]. Shanghai: Shanghai International Studies University, 2010

[3] He Kekang, CAI's Theoretical Foundation and Learning Centered PPT Design [J]. Chendu: Shichuan Education, 2001(1): 42-43

[4] Lin Kenan. Translational Teaching in Foreign Countries [J]. Chinese Translation, 2000 (2): 56-59

[5] Mei Deming, Investigation on Current Situation of Chinese English Teaching [M]. Shanghai, Shanghai International Studies University, 2004

[6] Wang Junhua, Market-oriented Interpreting Teaching [J]. Xi'an Institute of Foreign Languages. 2003 (4): 27-30

[7] Wang Xiangling, He Xiaolan. Processed Teaching Mode Based on Real Projects [J]. Shanghai: Shanghai Translation, 2008 (2): 52 